\title{
M Channels Containing KCNQ2 Subunits Modulate Norepinephrine, Aspartate, and GABA Release from Hippocampal Nerve Terminals
}

\author{
Maria Martire, ${ }^{1}$ Pasqualina Castaldo, ${ }^{2}$ Monia D'Amico, ${ }^{1}$ Paolo Preziosi, ${ }^{1}$ Lucio Annunziato, ${ }^{2}$ and Maurizio Taglialatela ${ }^{2}$ \\ ${ }^{1}$ Institute of Pharmacology, School of Medicine, Catholic University of Sacred Heart, 00168 Rome, Italy, and ${ }^{2}$ Division of Pharmacology, Department of \\ Neuroscience, School of Medicine, University of Naples Federico II, 80131 Naples, Italy
}

\begin{abstract}
KCNQ subunits encode for the M current $\left(I_{\mathrm{KM}}\right)$, a neuron-specific voltage-dependent $\mathrm{K}^{+}$current with a well established role in the control of neuronal excitability. In this study, by means of a combined biochemical, pharmacological, and electrophysiological approach, the role of presynaptic $I_{\mathrm{KM}}$ in the release of previously taken up tritiated norepineprine (NE), GABA, and D-aspartate (D-ASP) from hippocampal nerve terminals (synaptosomes) has been evaluated. Retigabine (RT) $(0.01-30 \mu \mathrm{M})$, a specific activator of $I_{\mathrm{KM}}$, inhibited $\left[{ }^{3} \mathrm{H}\right] \mathrm{NE},\left[{ }^{3} \mathrm{H}\right] \mathrm{D}-\mathrm{ASP}$, and $\left[{ }^{3} \mathrm{H}\right] \mathrm{GABA}$ release evoked by $9 \mathrm{~mm}$ extracellular $\mathrm{K}^{+}\left(\left[\mathrm{K}^{+}\right]_{\mathrm{e}}\right)$. RT-induced inhibition of $\left[{ }^{3} \mathrm{H}\right] \mathrm{NE}$ release was prevented by synaptosomal entrapment of polyclonal antibodies directed against KCNQ2 subunits, an effect that was abolished by antibody preabsorption with the KCNQ2 immunizing peptide; antibodies against KCNQ3 subunits were ineffective. Flupirtine (FP), a structural analog of RT, also inhibited $9 \mathrm{~mm}\left[\mathrm{~K}^{+}\right]_{\mathrm{e}}$-induced $\left[{ }^{3} \mathrm{H}\right] \mathrm{NE}$ release, although its maximal inhibition was lower than that of RT. Electrophysiological studies in KCNQ2-transfected Chinese hamster ovary cells revealed that RT and FP $(10 \mu \mathrm{M})$ caused a -19 and -9 $\mathrm{mV}$ hyperpolarizing shift, respectively, in the voltage dependence of activation of KCNQ2 $\mathrm{K}^{+}$channels. In the same cells, the cognition enhancer 10,10-bis(4-pyridinylmethyl)-9(10H)-anthracenone (XE-991) $(10 \mu \mathrm{M})$ blocked KCNQ2 channels and prevented their activation by RT (1-10 $\mu \mathrm{M})$. Finally, both XE-991 $(10-100 \mu \mathrm{M})$ and tetraethylammonium ions $(100 \mu \mathrm{M})$ abolished the inhibitory effect of RT $(1 \mu \mathrm{M})$ on $\left[{ }^{3} \mathrm{H}\right] \mathrm{NE}$ release. These findings provide novel evidence for a major regulatory role of $\mathrm{KCNQ} 2 \mathrm{~K}^{+}$channel subunits in neurotransmitter release from rat hippocampal nerve endings.
\end{abstract}

Key words: epilepsy; potassium channels; KCNQ2 subunits; retigabine; hippocampus; norepinephrine release

\section{Introduction}

$\mathrm{K}^{+}$channels control neuronal excitability by regulating interspike membrane potential, action potential waveform, and firing frequency. The $\mathrm{M}$ current $\left(I_{\mathrm{KM}}\right)$ is a slowly activating and noninactivating voltage-dependent $\mathrm{K}^{+}$current that repolarizes the neuronal membrane back toward the $\mathrm{K}^{+}$equilibrium potential $\left(E_{\mathrm{K}}\right)$ during long-lasting depolarizing inputs, thus limiting repetitive firing and causing spike-frequency adaptation (Brown and Adams, 1980). Receptor-dependent regulation of the M current is a primary mechanism by which neurotransmitters control neuronal excitability (Marrion, 1997). Heteromeric assembly of subunits encoded by two members of the KCNQ gene family, namely KCNQ2 and KCNQ3, recapitulate the functional properties of $I_{\mathrm{KM}}$ (Wang et

\footnotetext{
Received July 1, 2003; revised 0ct. 3, 2003; accepted 0ct. 31, 2003.

The present study was supported by grants from the Italian Ministry of the University and Research (Cofinanziamento 2001 and 2003, and Fondo per gli Investimenti della Ricerca di Base RBNE01XMP4 and RBNE01E7YX), the Italian Ministry of Health (Special Project "Alzheimer 2001/2004" and "Epilepsy 2003/2006"), Telethon (GP030209), European Commission (STREP n. 503038), and Regione Campania (Legge Regionale n. 5/2002 and Programma Operativo Regionale 2000/2006). We are deeply indebted to Prof. Thomas J. Jentsch (Zentrum fur Molekulare Neurobiologie, Hamburg, Germany) for KCNQ2 and KCNQ3 cDNAs.

Correspondence should be addressed to Dr. Maurizio Taglialatela, Division of Pharmacology, Department of Neuroscience, School of Medicine, University of Naples Federico II, Building 19, Via Pansini 5, 80131 Naples, Italy. E-mailmtaglia@unina.it.

DOI:10.1523/JNEUROSCI.3143-03.2004

Copyright $\odot 2004$ Society for Neuroscience $\quad$ 0270-6474/04/240592-06\$15.00/0
}

al., 1998), although KCNQ5 and possibly KCNQ4 subunits might also participate in $I_{\mathrm{KM}}$ heterogeneity (Rogawski, 2000).

$I_{\mathrm{KM}}$ plays a crucial role in epileptogenesis; mutations in $K C N Q 2$ or $K C N Q 3$ genes cause benign neonatal familial convulsions, a rare dominantly inherited form of human epilepsy (Jentsch, 2000). Furthermore, drug-induced enhancement of $I_{\mathrm{KM}}$ function may oppose epileptic activity; in fact, the novel anticonvulsant $N$-[2-amino-4-(4-fluorobenzylamino)-phenyl]-carbamic acid ethyl ester [retigabine (RT)], which is structurally unrelated to currently available antiepileptics, specifically activates voltage-gated $\mathrm{K}^{+}$currents carried by some members of the KCNQ family (Main et al., 2000; Rundfeldt and Netzer, 2000a; Wickenden et al., 2000). In keeping with a $\mathrm{K}^{+}$channel-opening mechanism, RT hyperpolarized and reduced repetitive firing of entorhinal cortical neurons in cortical slices (Hetka et al., 1999), inhibited firing of mouse primary cortical neurons (Otto et al., 2002), and activated native $I_{\mathrm{KM}}$ in rat sympathetic neurons (Tatulian et al., 2001). Together, these studies highlight the role of $I_{\mathrm{KM}}$ at the postsynaptic level. However, $I_{\mathrm{KM}}$ may also play a relevant presynaptic role; in fact, a drug class known as "cognition enhancers" increases neurotransmitter release by suppressing $I_{\mathrm{KM}}$ (for review, see Brown and Yu, 2000), and immunohistochemical studies have demonstrated a widespread presynaptic distribution of some KCNQ subunits within rodents and the human brain (Cooper et al., 2000, 2001). 
Because multiple KCNQ-type subunits underlie $I_{\mathrm{KM}}$, the aims of the present study have been: (1) to define the specific influence exerted by $I_{\mathrm{KM}^{-}}$-encoding KCNQ subunits in the release of previously taken up $1-\left[7,8-{ }^{3} \mathrm{H}\right]$ norepinephrine $\left(\left[{ }^{3} \mathrm{H}\right] \mathrm{NE}\right), \mathrm{D}-[2,3-$ $\left.{ }^{3} \mathrm{H}\right]$ aspartic acid $\left(\left[{ }^{3} \mathrm{H}\right] \mathrm{D}-\mathrm{ASP}\right)$, and 4 -amino- $\mathrm{N}$ - $\left[2,3-{ }^{3} \mathrm{H}\right]$ butyric acid $\left(\left[{ }^{3} \mathrm{H}\right] \mathrm{GABA}\right)$ from rat hippocampal presynaptic terminals and (2) to correlate the effects of $I_{\mathrm{KM}}$ modulators on KCNQ-type subunits expressed in Chinese hamster ovary $(\mathrm{CHO})$ cells with their ability to modulate neurotransmitter release. The results obtained, which showed that activation of $\mathrm{M}$ channels inhibited depolarization-induced neurotransmitter release and that blockade of KCNQ2 subunits prevented this inhibition, suggest that M channels containing KCNQ2 subunits are crucial regulators of neurotransmitter release from rat hippocampal nerve endings.

\section{Materials and Methods}

Synaptosomal preparation and release experiments. Synaptosomes were prepared from the hippocampi of adult male rats (Martire et al., 2000). In experiments with antibodies, these were entrapped into the synaptosomes during hippocampal tissue homogenization (1:100 dilution) (Raiteri et al., 2000). Synaptosomal pellets were resuspended in a medium containing the following (in $\mathrm{mm}$ ): $125 \mathrm{NaCl}, 3 \mathrm{KCl}, 1.2 \mathrm{MgSO}_{4}, 1.2$ $\mathrm{CaCl}_{2}, 1 \mathrm{NaH}_{2} \mathrm{PO} 4,22 \mathrm{NaHCO}_{3}$, and 10 glucose, $\mathrm{pH}$ 7.2-7.4, aerated with $95 \% \mathrm{O}_{2}$ and $5 \% \mathrm{CO}_{2}$ (standard medium). Synaptosomes were incubated for $15 \mathrm{~min}$ at $37^{\circ} \mathrm{C}$ with $0.04 \mu \mathrm{M}\left[{ }^{3} \mathrm{H}\right] \mathrm{NE}, 0.04 \mu \mathrm{M}\left[{ }^{3} \mathrm{H}\right] \mathrm{D}-\mathrm{ASP}$, or $0.02 \mu \mathrm{M}\left[{ }^{3} \mathrm{H}\right] \mathrm{GABA}$. Either $500 \mu \mathrm{M}$ dihydrokainic acid or $100 \mu \mathrm{M}$ $\beta$-alanine was added with $\left[{ }^{3} \mathrm{H}\right] \mathrm{D}$-ASP or $\left[{ }^{3} \mathrm{H}\right] \mathrm{GABA}$, respectively, to prevent glial uptake of the neurotransmitters (O'Shea, 2002; Raiteri et al., 2002). Identical aliquots of the synaptosomal suspension were placed at the bottom of parallel superfusion chambers maintained at $37^{\circ} \mathrm{C}$ and superfused $(0.6 \mathrm{ml} / \mathrm{min})$ with standard medium. In $\left[{ }^{3} \mathrm{H}\right] \mathrm{GABA}$ release experiments, $50 \mu \mathrm{M}$ amino-oxyacetic acid was added to prevent the catabolism of the neurotransmitter. After a 46 min equilibration period, perfusate fractions were collected every $2 \mathrm{~min}$; after collection of the first fraction (to measure basal release), synaptosomes were exposed for $3 \mathrm{~min}$ to a medium containing elevated $\mathrm{KCl}$ concentrations $(9,15,30$, or 50 $\mathrm{mm}$ ) plus different test drugs. Neurotransmitter efflux into the samples collected was calculated as a fractional rate. Drug effects were evaluated by determining the integrated area under the time course release curve (AUC) after subtraction of the area corresponding to basal release. Data, expressed as means \pm SEM, were analyzed by one-way ANOVA followed by Dunnett's multiple comparison test $(p<0.05)$.

Heterologous expression of KCNQ subunits. KCNQ2 or KCNQ3 subunits were expressed in CHO cells (Wickenden et al., 2000) by transient transfection with KCNQ2 or KCNQ3 cDNA, respectively, using Lipofectamine 2000 (Invitrogen, Milan, Italy). Enhanced green fluorescent protein (Clontech, Palo Alto, CA) was used as a transfection marker. For electrophysiological and biochemical experiments, the cells were seeded on glass coverslips, transfected after $24 \mathrm{hr}$, and analyzed 1-2 d after transfection.

Electrophysiology. Currents were recorded at room temperature (20$22^{\circ} \mathrm{C}$ ) using an Axopatch 200A amplifier and pClamp 6.0.4 software (Axon Instruments, Foster City, CA). The "perforated-patch" configuration of the patch-clamp technique was adopted using glass micropipettes of 2-3 M $\Omega$ resistance, because KCNQ2 currents showed a fast "run-down" in the conventional whole-cell mode (Shah et al., 2002). The extracellular solution contained the following (in $\mathrm{mm}$ ): $150 \mathrm{NaCl}, 2$ $\mathrm{CaCl}_{2}, 2 \mathrm{KCl}, 1 \mathrm{MgCl}_{2}, 11$ glucose, and $10 \mathrm{HEPES}$, pH 7.4, with $\mathrm{NaOH}$. Increases in $[\mathrm{KCl}]_{\mathrm{e}}$ were compensated with equimolar decreases in $[\mathrm{NaCl}]_{\mathrm{e}}$. The intracellular (pipette) solution contained the following (in $\mathrm{mm}$ ): $120 \mathrm{KCl}, 2 \mathrm{MgCl}_{2}, 10 \mathrm{EGTA}, 10 \mathrm{HEPES}, 1 \mathrm{Mg}$-ATP, and $0.25 \mathrm{~mm}$ cAMP, pH 7.3-7.4, with KOH. Nystatin $(120-240 \mu \mathrm{g} / \mathrm{ml})$ was added to this solution immediately before each recording session. KCNQ2 channels were activated by means of voltage ramps from $-100 \mathrm{mV}$ to 0 or $+20 \mathrm{mV}$ at a $0.5-1 \mathrm{sec} / 20 \mathrm{mV}$ speed and a frequency of $0.05 \mathrm{~Hz}$. Given the small volume of the recording chamber $(\approx 200 \mu \mathrm{l})$ and the fast perfusion speed $(1 \mathrm{ml} / \mathrm{min})$, solution exchanges were complete after two to three pulses. To quantify drug effects on KCNQ2 channels, the integrated AUCs of ramp-evoked $\mathrm{K}^{+}$currents recorded from KCNQ2-transfected cells in the presence of $\operatorname{drug}(\mathrm{s})$ were expressed as a percentage of the AUCs of ramp-evoked $\mathrm{K}^{+}$currents recorded in control conditions.

Indirect immunofluorescence. Cells were fixed with $4 \%$ formaldehyde for $20 \mathrm{~min}$ at room temperature and permeabilized with $0.1 \%$ Triton $\mathrm{X}-100$ in PBS. Cells were labeled with the appropriate primary antibodies (1:200 dilution) followed by rhodamine-conjugated secondary antibodies (Jackson ImmunoResearch, West Grove, PA) and analyzed on an Eclipse 400 photomicroscope (Nikon, Tokyo, Japan) with a $60 \times$ objective.

Materials. $\left[{ }^{3} \mathrm{H}\right] \mathrm{NE}$ (specific activity, $36.0 \mathrm{Ci} / \mathrm{mmol}$ ), $\left[{ }^{3} \mathrm{H}\right] \mathrm{GABA}$ (specific activity, $100 \mathrm{Ci} / \mathrm{mmol}$ ), and $\left[{ }^{3} \mathrm{H}\right] \mathrm{D}-\mathrm{ASP}$ (specific activity, $13.0 \mathrm{Ci}$ / $\mathrm{mmol}$ ) were from Amersham Biosciences (Buckinghamshire, UK). Retigabine and ethyl-2-amino-6-[4-(4-fluorbenzyl)amino]-pyridine-3carbamic acid maleate [flupirtine (FP)] were from ASTA Medica (Radebeul, Germany). 10,10-bis(4-pyridinylmethyl)-9(10H)-anthracenone (XE-991) was from DuPont NEN (Wilmington, DE). KCNQ2- and KCNQ3-specific antibodies (sc-7793 and sc-7795, respectively) and neutralizing peptides were from Santa Cruz Biotechnology (Santa Cruz, CA).

\section{Results \\ RT inhibits previously taken up $\left[{ }^{3} \mathrm{H}\right]$ neurotransmitter release from isolated nerve endings}

Synaptosomal release of $\left[{ }^{3} \mathrm{H}\right]$ neurotransmitters is exquisitely sensitive to mild depolarizing stimuli such as those produced by small changes in extracellular $\mathrm{K}^{+}\left(\left[\mathrm{K}^{+}\right]_{\mathrm{e}}\right)$. In fact, a 3 min exposure of hippocampal synaptosomes to $9 \mathrm{~mm}\left[\mathrm{~K}^{+}\right]_{\mathrm{e}}$ enhanced the release of previously taken up $\left[{ }^{3} \mathrm{H}\right] \mathrm{NE}$ (Fig. $1 \mathrm{~A}$ ). RT $(0.01-30$ $\mu \mathrm{M})$ dose-dependently inhibited $9 \mathrm{~mm}\left[\mathrm{~K}^{+}\right]_{\mathrm{e}}$-elicited $\left[{ }^{3} \mathrm{H}\right] \mathrm{NE}$ release, with a maximal inhibition $\left(E_{\mathrm{Max}}\right)$ of $42.2 \pm 2.1 \%$ and an $\mathrm{EC}_{50}$ of $1.00 \pm 0.06 \mu \mathrm{M}$ (Fig. $1 A, B$ ). No effect was exerted by RT on basal $\left[{ }^{3} \mathrm{H}\right] \mathrm{NE}$ release (data not shown). RT also inhibited $\left[{ }^{3} \mathrm{H}\right] \mathrm{NE}$ release from cortical synaptosomes with a potency and efficacy similar to that seen in hippocampal nerve terminals $\left(E_{\mathrm{Max}}, 41.3 \pm 2.3 \% ; \mathrm{EC}_{50}, 1.00 \pm 0.06\right.$; data not shown $)$. Furthermore, in hippocampal synaptosomes, $\left[{ }^{3} \mathrm{H}\right] \mathrm{NE}$ release evoked by exposure to $100 \mu \mathrm{M}$ 4-aminopyridine (4-AP) (AUC, $16.58 \pm$ $1.16 \%)$ was also inhibited by RT $\left(E_{\mathrm{Max}}, 43.5 \pm 2.1 \% ; \mathrm{EC}_{50}, 1.13 \pm\right.$ $0.05 \mu \mathrm{M}$; data not shown).

To verify whether RT also inhibited the release of other hippocampal neurotransmitters, we evaluated its effects on the release of glutamate and GABA. To label glutamatergic terminals, $\left[{ }^{3} \mathrm{H}\right]_{\mathrm{D}}$-ASP was used because it is more resistant to catabolism (Davies and Johnston, 1976); furthermore, synaptosomal $\left[{ }^{3} \mathrm{H}\right] \mathrm{D}-$ ASP uptake (Gundersen et al., 1995) and release (Martire et al., 2000) resemble that of endogenous glutamate. RT (0.01-30 $\mu \mathrm{M})$ dose-dependently inhibited both $\left[{ }^{3} \mathrm{H}\right] \mathrm{D}-\mathrm{ASP}$ and $\left[{ }^{3} \mathrm{H}\right]$ GABA release evoked by $9 \mathrm{~mm}\left[\mathrm{~K}^{+}\right]_{\mathrm{e}}$ from hippocampal synaptosomes (Fig. $1 B$ ), with an $E_{\mathrm{Max}}$ and an $\mathrm{EC}_{50}$ of $45.5 \pm 3.3 \%$ and $1.10 \pm$ $0.36 \mu \mathrm{M}$ for $\left[{ }^{3} \mathrm{H}\right] \mathrm{D}-\mathrm{ASP}$ and $47.8 \pm 2.9 \%$ and $1.08 \pm 0.06 \mu \mathrm{M}$ for $\left[{ }^{3} \mathrm{H}\right] \mathrm{GABA}$, respectively.

\section{$\mathrm{K}^{+}$channel-containing KCNQ2 subunits underlie RT- induced inhibition of hippocampal $\left[{ }^{3} \mathrm{H}\right] \mathrm{NE}$ release}

To confirm that $\mathrm{M}$ channels were involved in RT-induced inhibition of synaptosomal neurotransmitter release, and to identify the contribution of specific KCNQ subunits, we used commercially available polyclonal antibodies specifically directed against KCNQ2 or KCNQ3 subunits. Immunofluorescence experiments revealed that anti-KCNQ2 antibodies labeled CHO cells transfected with KCNQ2 but not with KCNQ3 cDNAs, whereas the opposite was observed with anti-KCNQ3 antibodies (Fig. $2 A$ ). In both cases, labeling was abolished by antibody preabsorption 


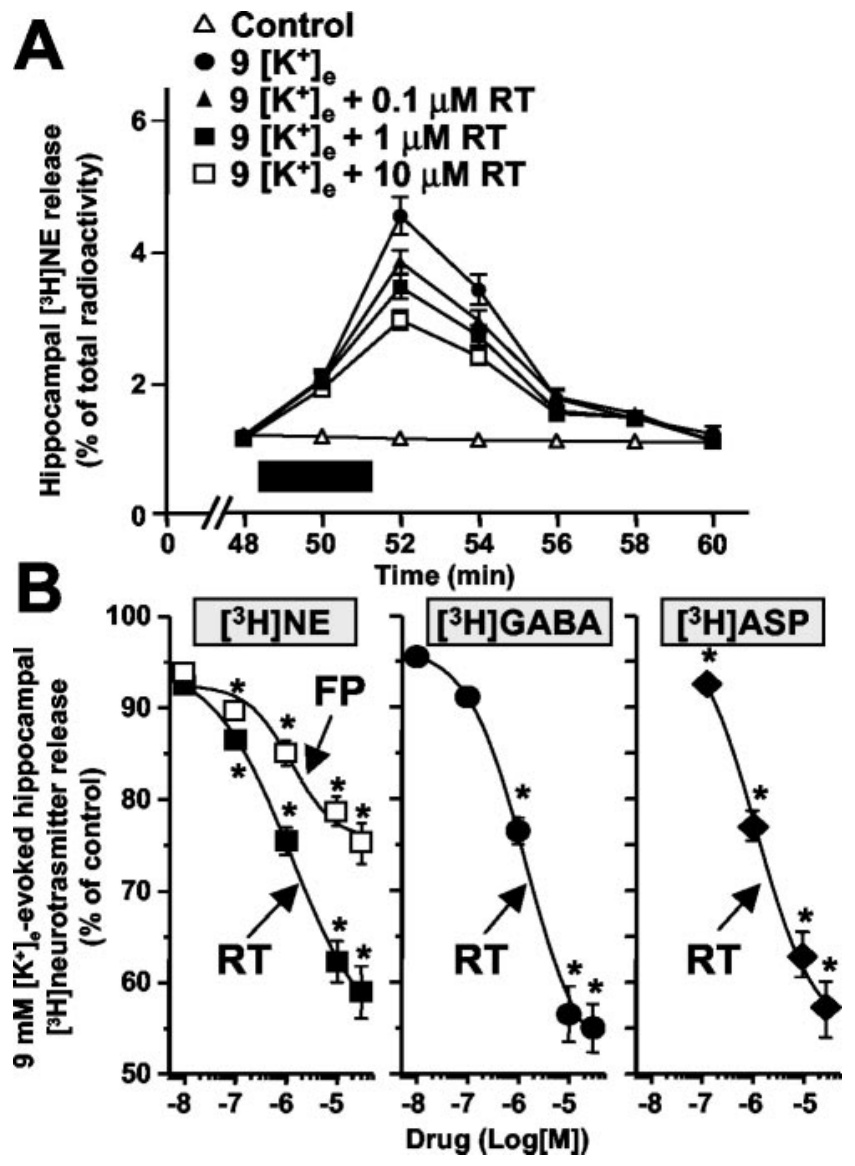

Figure 1. Effect of RT and FP on $\left[{ }^{3} \mathrm{H}\right]$ neurotransmitter release from hippocampal synaptosomes. A, Time course and dose dependence of RT-induced inhibition of [ $\left.{ }^{3} \mathrm{H}\right] \mathrm{NE}$ release. Synaptosomes were exposed to $9 \mathrm{~mm}\left[\mathrm{~K}^{+}\right]_{\mathrm{e}}$ with or without the indicated concentrations of RT for 3 min (boxed region). $B, R T$ (filled symbols)-induced and FP (open symbols)-induced inhibition of [ $\left.{ }^{3} \mathrm{H}\right] \mathrm{NE}$ (squares), $\left[{ }^{3} \mathrm{H}\right] \mathrm{GABA}$ (circles), and $\left[{ }^{3} \mathrm{H}\right] \mathrm{D}-\mathrm{ASP}$ (diamonds) release evoked by $9 \mathrm{~mm}$ $\left[\mathrm{K}^{+}\right]_{\mathrm{e}}$. Results are expressed as the percentage of inhibition produced by each drug concentration of the integrated AUCs of $\left[{ }^{3} \mathrm{H}\right]$ neurotransmitter release evoked by $9 \mathrm{~mm}\left[\mathrm{~K}^{+}\right]_{\mathrm{e}}\left(\left[^{3} \mathrm{H}\right] \mathrm{NE}\right.$, $\left.6.85 \pm 0.48 \% ;\left[{ }^{3} \mathrm{H}\right] \mathrm{D}-\mathrm{ASP}, 2.15 \pm 0.15 \% ;\left[{ }^{3} \mathrm{H}\right] \mathrm{GABA}, 3.90 \pm 0.27 \%\right)$. Values are means \pm SEM of $5-10$ separate experiments run in triplicate. ${ }^{*} p<0.05$ versus respective control.

with the respective immunizing peptide, arguing in favor of a specific interaction between these antibodies and KCNQ subunits. Notably, these antibodies were also used to detect KCNQ2 and KCNQ3 subunits in immunocytochemistry experiments in native rat hippocampal neurons (Shah et al., 2002). These results suggest that both antibodies bind to KCNQ subunit epitopes in their native, nondenatured conformation, making them useful tools to dissect the role of KCNQ subunits in synaptosomal $\left[{ }^{3} \mathrm{H}\right] \mathrm{NE}$ release. Because both antibodies recognized intracellular epitopes, we used the synaptosomal entrapping technique, which allows membrane-impermeant proteins to gain access to the synaptosomal cytoplasm (Raiteri et al., 2000). Synaptosomal entrapment of anti-KCNQ2 antibodies completely prevented $1 \mu \mathrm{M}$ RTinduced inhibition of $9 \mathrm{~mm}\left[\mathrm{~K}^{+}\right]_{\mathrm{e}}$-evoked hippocampal $\left[{ }^{3} \mathrm{H}\right] \mathrm{NE}$ release (Fig. $2 \mathrm{~B}$ ), an effect that was abolished after antibody preabsorption, before entrapment, with the KCNQ2 immunizing peptide; in contrast, anti-KCNQ3 antibodies were ineffective. Entrapment of both anti-KCNQ2 and anti-KCNQ3 antibodies also abolished RT-induced inhibition of $9 \mathrm{~mm}\left[\mathrm{~K}^{+}\right]_{\mathrm{e}}$-evoked $\left[{ }^{3} \mathrm{H}\right] \mathrm{NE}$ release.

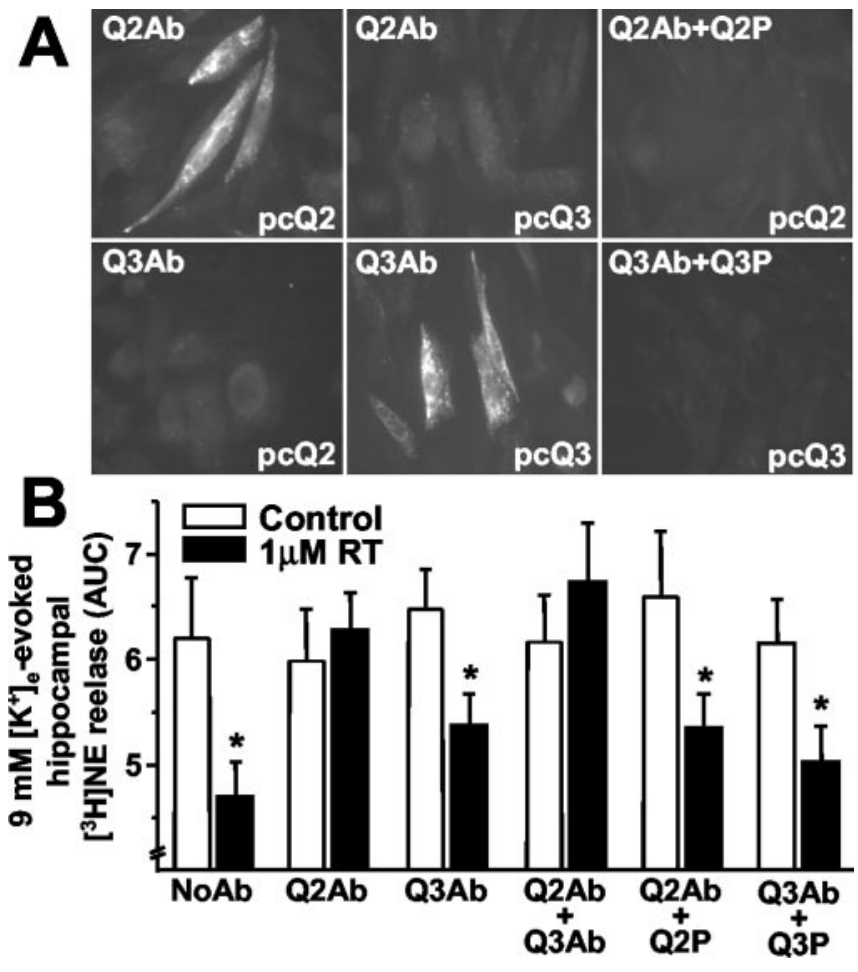

Figure 2. Antibody (Ab) characterization by immunocytochemistry in transfected $\mathrm{CHO}$ cells and effects on RT-induced inhibition of hippocampal [ $\left.{ }^{3} \mathrm{H}\right] \mathrm{NE}$ release. $A$, Immunocytochemistry in CHO cells. Anti-KCNQ antibodies (1:200 dilution) were probed with (Q2Ab + Q2P; Q3Ab + Q3P) or without (Q2Ab; $Q 3 A b)$ preabsorption with the respective immunizing peptides in cells transfected with KCNQ2 (pcQ2) or KCNQ3 (pcQ3) CDNAs, as indicated in each respective panel. B, Effects of antibodies on [ $\left.{ }^{3} \mathrm{H}\right] \mathrm{NE}$ release. Hippocampi were homogenized in the absence (NoAb) or in the presence of anti-KCNQ2 (Q2Ab), anti-KCNQ3 (Q3Ab), or anti-KCNQ2 plus anti-KCNQ3 (Q2Ab+Q3Ab) antibodies; when indicated, the antibodies were preabsorbed with the respective immunizing peptides (Q2P and Q3P; antibody:peptide ratio, 1:2). Data are the mean \pm SEM of 3-12 experiments run in triplicate. Asterisks denote values of RT-treated synaptosomes that are significantly different $(p<0.05)$ from their respective controls (no RT treatment).

RT-induced inhibition of hippocampal $\left[{ }^{3} \mathrm{H}\right] \mathrm{NE}$ release is dependent on $\left[\mathrm{K}^{+}\right]_{\mathrm{e}}$

Depolarization of hippocampal synaptosomes with increasing $\left[\mathrm{K}^{+}\right]_{\mathrm{e}}$ progressively enhanced $\left[{ }^{3} \mathrm{H}\right] \mathrm{NE}$ outflow; the ability of 10 $\mu \mathrm{M}$ RT to inhibit the release of the catecholamine decreased with increasing $\left[\mathrm{K}^{+}\right]_{\mathrm{e}}$ (Fig. 3A). To investigate whether RT interference with KCNQ2 channels depended on $\left[\mathrm{K}^{+}\right]_{\mathrm{e}}$, electrophysiological studies in KCNQ2-transfected $\mathrm{CHO}$ cells were performed to assess the effects of RT on KCNQ2 $\mathrm{K}^{+}$channel activity with 2 and $50 \mathrm{~mm}\left[\mathrm{~K}^{+}\right]_{\mathrm{e}}$. In the presence of $2 \mathrm{~mm}\left[\mathrm{~K}^{+}\right]_{\mathrm{e}}, 10 \mu \mathrm{M} \mathrm{RT}$ hyperpolarized the voltage dependence of $\mathrm{KCNQ} 2 \mathrm{~K}^{+}$channel activation by $-19.6 \pm 0.9 \mathrm{mV}(n=13)$ (Fig. $3 B)$. In fact, KCNQ2 currents reached $10 \%$ of the peak at $-40 \pm 1.9 \mathrm{mV}$ in controls and at $-60.3 \pm 2.2 \mathrm{mV}$ after exposure to $10 \mu \mathrm{M} \mathrm{RT}(p<0.05)$ (Fig. $3 B)$. A similar negative shift of $-16.7 \pm 1.6 \mathrm{mV}$ in the voltage dependence of activation of KCNQ2 currents was induced by $10 \mu \mathrm{M}$ RT when $50 \mathrm{mM}\left[\mathrm{K}^{+}\right]_{\mathrm{e}}$ was used (controls, $-63.8 \pm 3.1 \mathrm{mV} ; 10 \mu \mathrm{M}$ $\mathrm{RT},-80.5 \pm 3.6 \mathrm{mV} ; n=4 ; p<0.05)$. Thus, RT hyperpolarized the activation threshold of KCNQ2 $\mathrm{K}^{+}$channels regardless of $\left[\mathrm{K}^{+}\right]_{\mathrm{e}}$, arguing against a possible displacement of RT binding to KCNQ2 subunits with increasing $\left[\mathrm{K}^{+}\right]_{\mathrm{e}}$. Interestingly, the RT-induced KCNQ2 $\mathrm{K}^{+}$current enhancement was maximal at approximately $-65 \mathrm{mV}$, a value close to $E_{\mathrm{K}}$ in the presence of $9 \mathrm{~mm}\left[\mathrm{~K}^{+}\right]_{\mathrm{e}}$, although it declined progressively with increasing depolarizations, becoming negligible at approximately $-20 \mathrm{mV}$, a value close to $E_{\mathrm{K}}$ in the presence of $50 \mathrm{~mm}\left[\mathrm{~K}^{+}\right]_{\mathrm{e}}$ (Fig. 3C). 


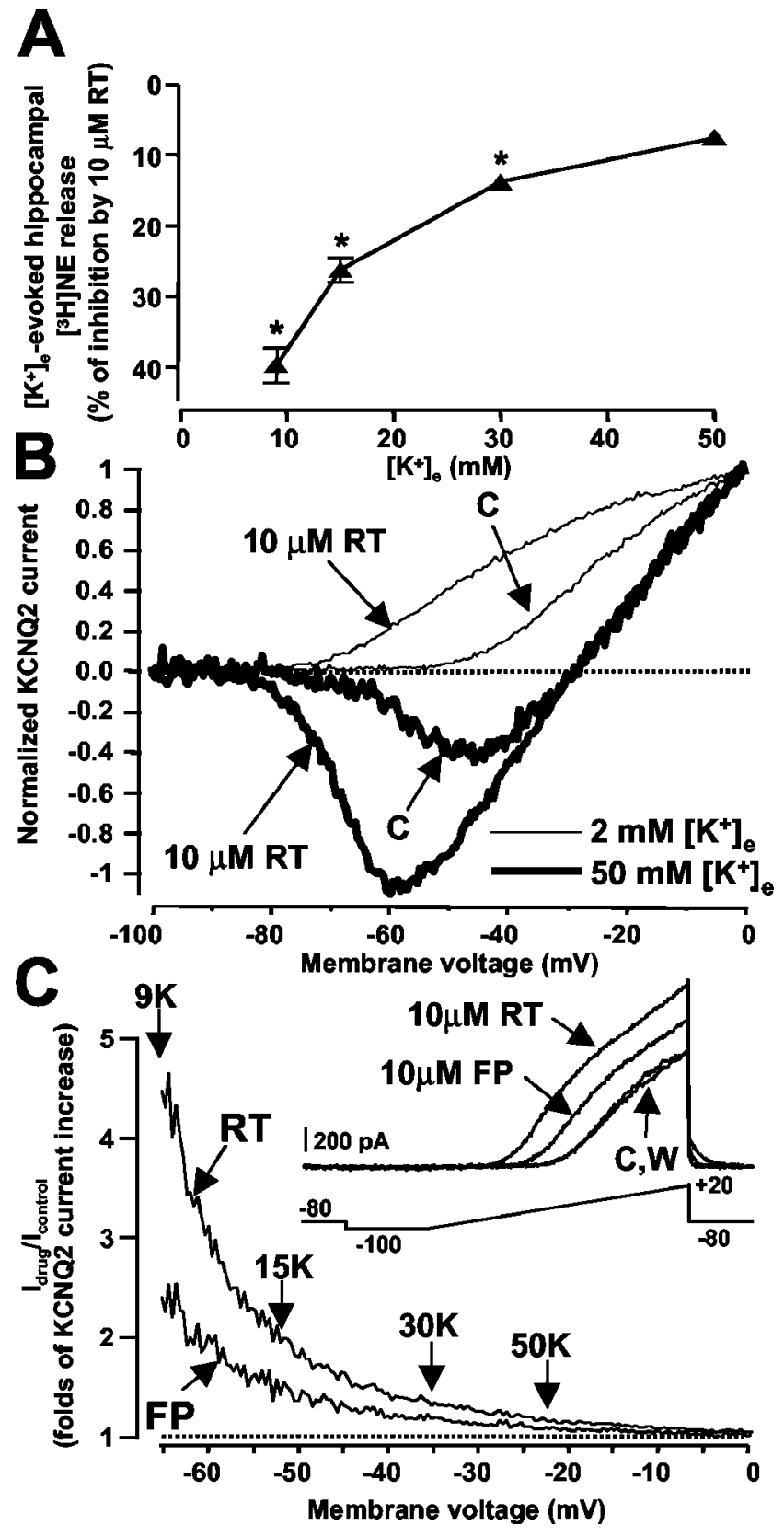

Figure 3. Effects of RT and FP on $\mathrm{K}^{+}$-evoked release of hippocampal $\left[{ }^{3} \mathrm{H}\right] \mathrm{NE}$ release and on KCNQ2 channels expressed in CHO cells. $A$, Effects of $10 \mu \mathrm{M}$ RT on [ $\left.{ }^{3} \mathrm{H}\right] \mathrm{NE}$ release evoked by increasing $\left[\mathrm{K}^{+}\right]_{\mathrm{e}}$. The integrated AUCs of hippocampal $\left[{ }^{3} \mathrm{H}\right] \mathrm{NE}$ release were $6.08 \pm 0.42$, $12.95 \pm 0.78,18.20 \pm 1.26$, and $23.60 \pm 1.65 \%$ of total synaptosomal radioactivity with 9 , 15,30 , and $50 \mathrm{~mm}\left[\mathrm{~K}^{+}\right]_{e}$, respectively. Filled triangles are the percentage of RT $(10 \mu \mathrm{M})$ induced inhibition of depolarization-induced $\left[{ }^{3} \mathrm{H}\right] \mathrm{NE}$ release observed at the indicated $\left[\mathrm{K}^{+}\right]_{\mathrm{e}}$. Data represent the mean \pm SEM of three experiments run in triplicate. ${ }^{*} p<0.05$ versus respective controls. B, Effect of $10 \mu \mathrm{M} R$ RT on KCNQ2 channels with 2 and $50 \mathrm{~mm}\left[\mathrm{~K}^{+}\right]_{\mathrm{e}}$. Representative voltage ramp-evoked current traces from a single KCNQ2-transfected cell are recorded in $2 \mathrm{~mm}$ (thin lines) or $50 \mathrm{~mm}$ (thick lines) $\left[\mathrm{K}^{+}\right]_{\mathrm{e}}$. C, Enhancement of KCNQ2 $\mathrm{K}^{+}$currents by RT and FP is maximal at negative membrane potentials. KCNQ2 $\mathrm{K}^{+}$currents $\left(2 \mathrm{~mm}\left[\mathrm{~K}^{+}\right]_{\mathrm{e}}\right)$ were activated by the voltage-ramp protocol described in Materials and Methods under control conditions (C), after exposure to $10 \mu \mathrm{m} R$ T or to $10 \mu \mathrm{m} F$ P and after washout (W), as indicated in the inset. After normalization to the maximal value, the currents recorded in the presence of the drug were divided by the control currents, and the results were expressed as a function of membrane potential. The vertical arrows indicate the theoretical $E_{\mathrm{K}}$ values predicted by the Nernst equation $\left(E_{K}=R T / F \times \ln \left[K^{+}\right]_{e} /\left[K^{+}\right]_{i}\right)$ in the presence of the indicated $\left[K^{+}\right]_{e} \cdot \ln$, Logarithm. Similar results were obtained in four cells with $10 \mu \mathrm{m} R T$ and in three cells with 10 $\mu \mathrm{MFP}$.

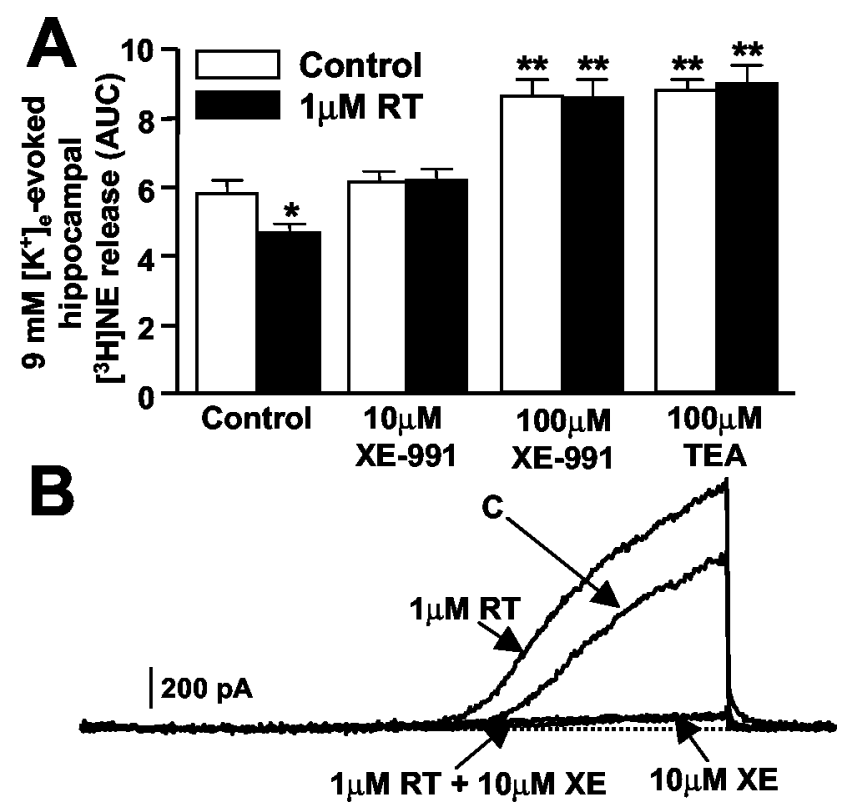

Figure 4. XE-991 and TEA prevent RT-induced inhibition of $9 \mathrm{~mm} \mathrm{~K}^{+}$-evoked hippocampal $\left[{ }^{3} \mathrm{H}\right] \mathrm{NE}$. A, Effect of RT on $9 \mathrm{~mm} \mathrm{~K}{ }^{+}$-evoked [ $\left.{ }^{3} \mathrm{H}\right] \mathrm{NE}$ release in the presence of XE-991 or TEA. $\left[{ }^{3} \mathrm{H}\right] \mathrm{NE}$ release was evaluated with (filled bars) or without (open bars) $1 \mu \mathrm{M}$ RT in synaptosomes that had been preincubated for $8 \mathrm{~min}$ with XE-991 (10 or $100 \mu \mathrm{M})$ or TEA $(100 \mu \mathrm{M})$, as indicated. Each bar is the mean \pm SEM of three to four experiments performed in triplicate. ${ }^{*} p<0.05$ versus respective control; ${ }^{* *} p<0.05$ versus controls without drug (XE-991 or TEA) preincubation but not different from each other. B, RT does not counteract XE-991 (XE)-induced $\mathrm{K}^{+}$ current blockade in $\mathrm{KCNQ2}$-transfected $\mathrm{CHO}$ cells. Representative ramp-evoked $\mathrm{K}^{+}$currents from a single KCNQ2-transfected cell were recorded under control conditions and after subsequent perfusion with $1 \mu \mathrm{M}$ RT, $10 \mu \mathrm{M}$ XE-991, and $10 \mu \mathrm{M}$ XE-991 plus $1 \mu \mathrm{m}$ RT (3- 4 min each; see Results).

Hippocampal $\left[{ }^{3} \mathrm{H}\right] \mathrm{NE}$ release is influenced by $I_{\mathrm{KM}}$ modulators

The nonopioid analgesic FP $(0.01-30 \mu \mathrm{M})$, a structural analog of RT (Friedel and Fitton, 1993), inhibited $9 \mathrm{~mm}\left[\mathrm{~K}^{+}\right]_{\mathrm{e}}$-induced $\left[{ }^{3} \mathrm{H}\right] \mathrm{NE}$ release from hippocampal synaptosomes; when compared with RT, FP appeared to be equipotent $\left(\mathrm{EC}_{50}, 1.27 \pm 0.08\right.$ $\mu \mathrm{M})$ but less effective $\left(E_{\mathrm{Max}}, 24.7 \pm 1.5 \%\right)$ (Fig. $\left.1 B\right)$. Electrophysiological studies in KCNQ2-transfected cells showed that $10 \mu \mathrm{M}$ FP caused a voltage-dependent hyperpolarizing shift in KCNQ2 activation threshold of $-9 \pm 1 \mathrm{mV}(n=4)$, approximately half that caused by RT (Fig. 3C); furthermore, just as with RT, maximal FP-induced current enhancement was observed at potentials of approximately $-65 \mathrm{mV}$ (Fig. 3C).

Low micromolar concentrations of the cognition enhancer XE-991 (Zaczek et al., 1998) specifically inhibit $\mathrm{K}^{+}$channels formed by KCNQ-type subunits (Wang et al., 1998). XE-991 $(10-100 \mu \mathrm{M})$ completely prevented the inhibitory effects on 9 mm $\left[\mathrm{K}^{+}\right]_{\mathrm{e}}$-induced $\left[{ }^{3} \mathrm{H}\right] \mathrm{NE}$ release exerted by $1 \mu \mathrm{M} \mathrm{RT}$ (Fig. $4 A$ ). These findings are consistent with those obtained in $\mathrm{CHO}$ cells, in which XE-991 blocked KCNQ2 $\mathrm{K}^{+}$channels and essentially prevented their activation by RT (Fig. $4 B$ ). In fact, in the absence of XE-991, the integrated AUCs of ramp-evoked KCNQ2 $\mathrm{K}^{+}$currents were $163.5 \pm 9.6$ and $211.6 \pm 15.9 \%$ with 1 and $10 \mu \mathrm{M}$ RT, respectively, compared with control KCNQ2 currents $(n=4 ; p<$ 0.05 vs controls); in the presence of $10 \mu \mathrm{M}$ XE-991, these values were $6.1 \pm 2.7,10.9 \pm 2.1$, and $12.8 \pm 3.6 \%$ of control KCNQ2 currents with 0,1 , and $10 \mu \mathrm{M} R$, respectively $(n=4 ; p<0.05$ vs controls).

M channels containing KCNQ2 subunits are exquisitely sensitive to blockade by submillimolar concentrations of tetraethyl- 
ammonium ions (TEA), whereas KCNQ3-containing channels are highly resistant (Wang et al., 1998). The fact that $100 \mu \mathrm{M}$ TEA completely prevented RT-induced inhibition (Fig. $4 \mathrm{~A}$ ) provided strong support for the hypothesis that KCNQ2-type subunits were involved in RT-induced inhibition of NE release. Furthermore, $100 \mu \mathrm{M}$ TEA, similar to $100 \mu \mathrm{M}$ XE-991, potentiated $9 \mathrm{~mm}$ $\left[\mathrm{K}^{+}\right]_{\mathrm{e}}$-evoked $\left[{ }^{3} \mathrm{H}\right] \mathrm{NE}$ release (Fig. $4 A$ ), possibly because at this concentration, both drugs inhibited other voltage-gated $\mathrm{K}^{+}$ channels controlling NE release (Wang et al., 1998).

\section{Discussion}

In the present study, we examined the possible role of presynaptic $\mathrm{M}$ channels in $\left[{ }^{3} \mathrm{H}\right]$ neurotransmitter release from hippocampal synaptosomes evoked by exposure to $9 \mathrm{mM}\left[\mathrm{K}^{+}\right]_{\mathrm{e}}$; neurotransmitter release induced by this small depolaring stimulus is entirely (as in the case of $\left[{ }^{3} \mathrm{H}\right] \mathrm{NE}$ ) or for the most part (as with $\left[{ }^{3} \mathrm{H}\right] \mathrm{D}$-ASP and $\left.\left[{ }^{3} \mathrm{H}\right] \mathrm{GABA}\right)$ calcium dependent and exocytotic in nature (Raiteri et al., 2002). Furthermore, dihydrokainate or $\beta$-alanine was used during synaptosomal labeling with $\left[{ }^{3} \mathrm{H}\right]_{\mathrm{D}}$ ASP and $\left[{ }^{3} \mathrm{H}\right] \mathrm{GABA}$, respectively, to prevent glial incorporation and subsequent release of labeled transmitters.

The $I_{\mathrm{KM}}$ activator RT produced a remarkable $(>40 \%)$ inhibition of depolarization-induced $\left[{ }^{3} \mathrm{H}\right] \mathrm{NE},\left[{ }^{3} \mathrm{H}\right] \mathrm{D}-\mathrm{ASP}$, and $\left[{ }^{3} \mathrm{H}\right] \mathrm{GABA}$ release evoked by $9 \mathrm{~mm}\left[\mathrm{~K}^{+}\right]_{\mathrm{e}}$. A similar degree of inhibition of $\left[{ }^{3} \mathrm{H}\right] \mathrm{NE}$ release was also observed when synaptosomes were isolated from the cerebral cortex or when hippocampal $\left[{ }^{3} \mathrm{H}\right] \mathrm{NE}$ release was triggered by 4 -AP, a nonselective blocker of various $\mathrm{K}^{+}$channel subtypes that does not significantly affect $I_{\mathrm{KM}}$ (Robbins et al., 1992). The concentrations of RT required to inhibit $\left[{ }^{3} \mathrm{H}\right] \mathrm{NE}$ release $\left(\mathrm{EC}_{50} \approx 1 \mu \mathrm{M}\right)$ were comparable with those required to activate homomeric and heteromeric channels formed by KCNQ2, KCNQ3, KCNQ4, and KCNQ5 but not KCNQ1 subunits (Rundfeldt and Netzer, 2000a; Tatulian et al., 2001) and $\sim 30$ times lower than those needed to exert other neurochemical actions such as an enhancement of $\mathrm{GABA}_{\mathrm{A}}$ receptor-mediated postsynaptic currents (Rundfeldt and Netzer, 2000b; Otto et al., 2002).

The correspondence between the concentrations of RT inhibiting $\left[{ }^{3} \mathrm{H}\right] \mathrm{NE}$ release and those activating KCNQ-type channels strongly suggested that $\mathrm{KCNQ} \mathrm{K}^{+}$channels were involved in RT-induced inhibition of hippocampal neurotransmitter release. In agreement with this hypothesis, other $I_{\mathrm{KM}}$ modulators profoundly influenced hippocampal $\left[{ }^{3} \mathrm{H}\right] \mathrm{NE}$ release. In fact, the centrally acting nonopioid analgesic FP, a structural analog of RT, also inhibited $9 \mathrm{~mm}\left[\mathrm{~K}^{+}\right]_{\mathrm{e}}$-induced $\left[{ }^{3} \mathrm{H}\right] \mathrm{NE}$ release from hippocampal synaptosomes, although its efficacy was lower than that of RT. Our electrophysiological analysis revealed that in KCNQ2-transfected cells, FP hyperpolarized the voltage dependence of activation of KCNQ2 $\mathrm{K}^{+}$channels by $-9 \mathrm{mV}$, half that produced by $\mathrm{RT}(-19 \mathrm{mV})$, thus providing a plausible explanation for the lower efficacy of FP in modulating $\left[{ }^{3} \mathrm{H}\right] \mathrm{NE}$ release when compared with RT.

XE-991 is a novel cognition-enhancing compound with an anthracenone structural backbone (Zaczek et al., 1998) that selectively blocks KCNQ subunits (Wang et al., 1998). XE-991 counteracted both the RT-induced KCNQ2 channel activation and the inhibition of $9 \mathrm{~mm}\left[\mathrm{~K}^{+}\right]_{\mathrm{e}}$-enhanced hippocampal $\left[{ }^{3} \mathrm{H}\right] \mathrm{NE}$ release prompted by the antiepileptic compound. The lack of effect of $10 \mu \mathrm{M}$ XE-991 as well as of anti-KCNQ2 antibodies in enhancing $\left[{ }^{3} \mathrm{H}\right] \mathrm{NE}$ release evoked by $9 \mathrm{~mm}\left[\mathrm{~K}^{+}\right]_{\mathrm{e}}$ is in line with the results obtained by Vickroy (1993), who showed that the potentiation of $\left[{ }^{3} \mathrm{H}\right] \mathrm{ACh}$ release from hippocampal synaptosomes by the cognition enhancer linopirdine required higher
(15-30 mM) $\left[\mathrm{K}^{+}\right]_{\mathrm{e}}$. Thus, the small synaptosomal depolarization prompted by exposure to $9 \mathrm{mM}\left[\mathrm{K}^{+}\right]_{\mathrm{e}}$ seems insufficient to activate presynaptic $I_{\mathrm{KM}}$. As a matter of fact, the inhibitory effect of RT on hippocampal [ $\left.{ }^{3} \mathrm{H}\right] \mathrm{NE}$ release was inversely correlated with the $\left[\mathrm{K}^{+}\right]_{\mathrm{e}}$ triggering the release of the catecholamine. The negative shift in KCNQ2 voltage dependence of activation produced by $\mathrm{RT}$ regardless of $\left[\mathrm{K}^{+}\right]_{\mathrm{e}}$ (Tatulian et al., 2001) predicted that the influence of RT on hippocampal $\left[{ }^{3} \mathrm{H}\right] \mathrm{NE}$ release would be maximal when relatively low $(9 \mathrm{mM})\left[\mathrm{K}^{+}\right]_{\mathrm{e}}$ is used to trigger neurotransmitter release. In fact, at relatively negative values of $E_{\mathrm{M}}$ (less than $-60 \mathrm{mV}$ ), RT would dramatically increase the activity of KCNQ2 channels, enhancing their participation in synaptosomal membrane potential control. In contrast, the effects of RT would be negligible when $\left[{ }^{3} \mathrm{H}\right] \mathrm{NE}$ release is elicited by higher $\left[\mathrm{K}^{+}\right]_{\mathrm{e}}$, because stronger depolarizations (an $E_{\mathrm{M}}$ greater than -30 $\mathrm{mV}$ ) would already cause a maximal degree of KCNQ2 $\mathrm{K}^{+}$channel activation. Although other factors (swelling and $\mathrm{Ca}^{2+}$ release from internal sources) may also influence neurotransmitter release evoked by high $(>9 \mathrm{~mm})\left[\mathrm{K}^{+}\right]_{\mathrm{e}}$ (Raiteri et al., 2002), these results suggest that $I_{\mathrm{KM}}$ controls depolarization-induced neurotransmitter release.

Synaptosomal entrapment experiments with KCNQ-specific antibodies revealed that KCNQ2 subunits play a major role in RT-induced modulation of depolarization-induced $\left[{ }^{3} \mathrm{H}\right] \mathrm{NE}$ release. The negative results of the release experiments with antiKCNQ3 antibodies cannot rule out the involvement of KCNQ3 subunits in neurotransmitter release. In fact, we cannot exclude the possibility that in our experiments, the intraterminal concentration of these antibodies might not have been sufficient for binding to KCNQ3, or that despite effectively binding to KCNQ3, they might not have blocked the activity of this $\mathrm{K}^{+}$ channel subunit. However, the fact that TEA, when used at a concentration $(100 \mu \mathrm{M})$ that specifically inhibited $\mathrm{M}$ channels containing KCNQ2 subunits (Wang et al., 1998), completely counteracted RT-induced inhibition of $\left[{ }^{3} \mathrm{H}\right] \mathrm{NE}$ release further underlies the contribution of KCNQ2 subunits in hippocampal neurotransmitter release. Interestingly, KCNQ2 and KCNQ3 subunit expression has been found postsynaptically on somata and dendrites of hippocampal and neocortical pyramidal and polymorphic neurons; in contrast, in the hippocampus, KCNQ2 but not KCNQ3 immunoreactivity is located presynaptically on axons and nerve terminals of the mossy fiber pathway in the dentate hilus and the stratum lucidum of the CA3 region in both mouse and human brain (Cooper et al., 2000, 2001). The expression of KCNQ2 subunits in axon terminals within CA1 and CA3 hippocampal subfields has been confirmed by immunoelectron microscopy in the macaque monkey brain (Fieles et al., 2002).

In conclusion, the present findings reveal a novel role for KCNQ2 subunit-containing M-type channels in the modulation of hippocampal $\left[{ }^{3} \mathrm{H}\right] \mathrm{NE},\left[{ }^{3} \mathrm{H}\right] \mathrm{D}-\mathrm{ASP}$, and $\left[{ }^{3} \mathrm{H}\right] \mathrm{GABA}$ release. The release of all three transmitters evoked by $9 \mathrm{~mm}\left[\mathrm{~K}^{+}\right]_{\mathrm{e}}$ is primarily calcium dependent (Raiteri et al., 2002); therefore, activation of presynaptic $I_{\mathrm{KM}}$ may hyperpolarize hippocampal nerve endings, thus reducing $\mathrm{Ca}^{2+}$ influx through multiple voltage-gated $\mathrm{Ca}^{2+}$ channels (Alvarez Maubecin et al., 1995). Because of its slow activation kinetics, $I_{\mathrm{KM}}$ would participate in presynaptic membrane potential control mainly during repetitive activity or prolonged depolarization such as that induced by increased $\left[\mathrm{K}^{+}\right]_{\mathrm{e}}$. Given the multiplicity of receptors regulating $I_{\mathrm{KM}}$, the modulation of presynaptic $\mathrm{M}$ channels containing KCNQ2 subunits may be a powerful means by which multiple neurotransmitters affect synaptic function in the hippocampus. Finally, additional work is needed to clarify whether the activa- 
tion of presynaptic $\mathrm{M}$ channels controlling neurotransmitter release contributes to the antiepileptic action of RT.

\section{References}

Alvarez Maubecin V, Sanchez VN, Rosato Siri MD, Cherksey BD, Sugimori M, Llinas R, Uchitel OD (1995) Pharmacological characterization of the voltage-dependent $\mathrm{Ca}^{2+}$ channels present in synaptosomes from rat and chicken central nervous system. J Neurochem 64:2544-2551.

Brown BS, Yu SP (2000) Modulation and genetic identification of the M channel. Prog Biophys Mol Biol 73:135-166.

Brown DA, Adams PR (1980) Muscarinic suppression of a novel voltage sensitive $\mathrm{K}^{+}$current in a vertebrate neurone. Nature 283:673-676.

Cooper EC, Aldape KD, Abosch A, Barbaro NM, Berger MS, Peacock WS, Jan YN, Jan LY (2000) Colocalization and coassembly of two human brain M-type potassium channel subunits that are mutated in epilepsy. Proc Natl Acad Sci USA 97:4914-4919.

Cooper EC, Harrington E, Jan YN, Jan LY (2001) M channel KCNQ2 subunits are localized to key sites for control of neuronal network oscillations and synchronization in mouse brain. J Neurosci 21:9529-9540.

Davies LP, Johnston GAR (1976) Uptake and release of D- and L-aspartate by rat brain slices. J Neurochem 26:1007-1014.

Fieles WE, Smith J, Christian EP, Cross A, Mrzljak L (2002) Subcellular localization of KCNQ2 potassium channel subunit in the macaque monkey cerebral cortex and hippocampus. Soc Neurosci Abstr 28:438.8.

Friedel HA, Fitton A (1993) Flupirtine. A review of its pharmacological properties, and therapeutic efficacy in pain states. Drugs 45:548-569.

Gundersen V, Shupliakov O, Brodin L, Ottersen OP, Storm-Mathisen J (1995) Quantification of excitatory amino acid uptake at intact glutamatergic synapses by immunocytochemistry of exogenous D-aspartate. J Neurosci 15:4417-4428.

Hetka R, Rundfeldt C, Heinemann U, Schmitz D (1999) Retigabine strongly reduces repetitive firing in rat entorhinal cortex. Eur J Pharmacol 386:165-171.

Jentsch TJ (2000) Neuronal KCNQ potassium channels: physiology and role in disease. Nat Rev Neurosci 1:21-30.

Main MJ, Cryan JE, Dupere JR, Cox B, Clare JJ, Burbidge SA (2000) Modulation of KCNQ2/3 potassium channels by the novel anticonvulsant retigabine. Mol Pharmacol 58:253-262.

Marrion NV (1997) Control of M-current. Annu Rev Physiol 59:483-504.

Martire M, Altobelli D, Maurizi S, Preziosi P, Fuxe K (2000) K ${ }^{+}$-evoked $\left[{ }^{3} \mathrm{H}\right] \mathrm{D}$-aspartate release in rat spinal cord synaptosomes: modulation by neuropeptide $\mathrm{Y}$ and calcium channel antagonists. J Neurosci Res 62:722-729.
O'Shea RD (2002) Roles and regulation of glutamate transporters in the central nervous system. Clin Exp Pharmacol Physiol 29:1018-1029.

Otto JF, Kimball MM, Wilcox KS (2002) Effects of the anticonvulsant retigabine on cultured cortical neurons: changes in electroresponsive properties and synaptic transmission. Mol Pharmacol 61:921-927.

Raiteri L, Stigliani S, Zedda L, Raiteri M, Bonanno G (2002) Multiple mechanisms of transmitter release evoked by "pathologically" elevated extracellular $[\mathrm{K}+]$ : involvement of transporter reversal and mitochondrial calcium. J Neurochem 80:706-714.

Raiteri M, Sala R, Fassio A, Rossetto O, Bonanno G (2000) Entrapping of impermeant probes of different size into nonpermeabilized synaptosomes as a method to study presynaptic mechanisms. J Neurochem 74:423-431.

Robbins J, Trouslard J, Marsh SJ, Brown DA (1992) Kinetic and pharmacological properties of the $\mathrm{M}$-current in rodent neuroblastoma $\times$ glioma hybrid cells. J Physiol (Lond) 451:159-185.

Rogawski MA (2000) KCNQ2/KCNQ3 $\mathrm{K}^{+}$channels and the molecular pathogenesis of epilepsy: implications for therapy. Trends Neurosci 23:393-398.

Rundfeldt C, Netzer R (2000a) The novel anticonvulsant retigabine activates $\mathrm{M}$-currents in Chinese hamster ovary-cells transfected with human KCNQ2/3 subunits. Neurosci Lett 282:73-76.

Rundfeldt C, Netzer R (2000b) Investigations into the mechanism of action of the new anticonvulsant retigabine. Interaction with GABAergic and glutamatergic neurotransmission and with voltage gated ion channels. Arzneimittelforschung 50:1063-1070.

Shah MM, Mistry M, Marsh SJ, Brown DA, Delmas P (2002) Molecular correlates of the M-current in cultured rat hippocampal neurons. J Physiol (Lond) 544:29-37.

Tatulian L, Delmas P, Abogadie FC, Brown DA (2001) Activation of expressed KCNQ potassium currents and native neuronal M-type potassium currents by the anti-convulsant drug retigabine. J Neurosci 21:5535-5545.

Vickroy TW (1993) Presynaptic cholinergic actions by the putative cognitive enhancing agent DuP 996. J Pharmacol Exp Ther 264:910-917.

Wang HS, Pan Z, Shi W, Brown BS, Wymore RS, Cohen IS, Dixon JE, McKinnon D (1998) KCNQ2 and KCNQ3 potassium channel subunits: molecular correlates of the M-channel. Science 282:1890-1893.

Wickenden AD, Yu W, Zou A, Jegla T, Wagoner PK (2000) Retigabine, a novel anticonvulsant, enhances activation of $\mathrm{KCNQ} 2 / 3$ potassium channels. Mol Pharmacol 58:591-600.

Zaczek R, Chorvat RJ, Saye JA, Pierdomenico ME, Maciag CM, Logue AR, Fisher BN, Rominger DH, Earl RA (1998) Two new potent neurotransmitter release enhancers, 10,10-bis(4-pyridinylmethyl)-9(10H)-anthracenone and 10,10-bis(2-fluoro-4-pyridinylmethyl)-9(10H)-anthracenone: comparison to linopirdine. J Pharmacol Exp Ther 285:724-730. 